\title{
You. Here. Now.
}

\author{
Ian Willcock \\ University of Hertfordshire \\ London, UK \\ i.willcock@herts.ac.uk
}

\section{INTRODUCTION}

You. Here. Now. is an interactive installation designed for gallery exhibition that explores ideas of temporal and locative contexts for ephemeral digital portraits and in so doing, translates viewers' images into visual representations that are simultaneously both individual and collective

The work trawls the websites of selected news organisations and downloads al the visual imagery it comes across. These images are then sampled to provide a large number of fragments, each of which reflects the preoccupations and priorities of the news gathering organisations, but which are (because of their size) prevented from functioning iconically; each is a fragment, which will usually suggest a larger context, but which will almost never present its references fully formed. The fragments are all catalogued; stored, together with their average colour value in a constantly evolving database. This is the palette from which the work constructs its portraits.

To engage with the work, all that is required is an investment of time; the passer-by must pause for a while. As they examine the piece, their portrait will gradually emerge from the background presentation of several hundred tiny fragments (which are in a continuous state of flux). Through the currency of its materials and specificity of its location, the resulting image is a portrait which is necessarily a product of a specific time. It carries within its basic materials references to wider narratives of power and place from which both the work and the portrait have emerged.

An earlier version of the piece was exhibited as part of the Illusion Festival in the Science Gallery, Dublin from July to September 2013.

\section{CONTEXT AND THE DIGITAL ARTIST}

In creating this work, I was concerned about the context for digital art and how that context might be translated into a differing experience for the viewer; for many works, there is no context other than that provided by the technical means of its presentation - the type of device or computer that it requires to be presented. Other than this, the work is the same in any part of the world, at any time, and for any viewer. As an artist interested in social process, this placing of artefacts and experiences outside of some of the usual means for developing cultural meaning and reference is troubling and unsatisfactory.

You. Here. Now. attempts to make the viewer's perception, together with the site of the installation, and the instant that the work is encountered essential parts of the experience of the artefact, to restore some of what Walter Benjamin called the Aura of a work; a set of referents that fix it in time and attest to its production and consumption. The user is required to pause in front of the piece and this investment of 'personal time' is rewarded as their image (portrait) gradually emerges from the swirling semi-random flow of imagery the work presents. The other essential source for the final appearance of a user's portrait is the wider context of societal pre-occupations at that point in time - as filtered into news stories published by major news organisations. The piece draws its materials for representing viewers in real-time from public news sites and hence translates a conventional (and highly familiar) image into one couched in terms of fragments of that imagery of the instant, thus ensuring that each experience is the result of both individual choice and collective, time-dependent preoccupations.

\section{REFERENCES}

Benjamin, W. (1936) The Work of Art in the Age of Mechanical Reproduction. In H. Arendt (ed.), Illuminations. Pimlico, London. 


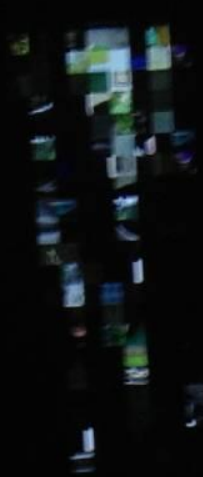

